\title{
George Dillman y las influencias en la teoría y práctica de los puntos de presión
}

Entrevista por Peter Hobart

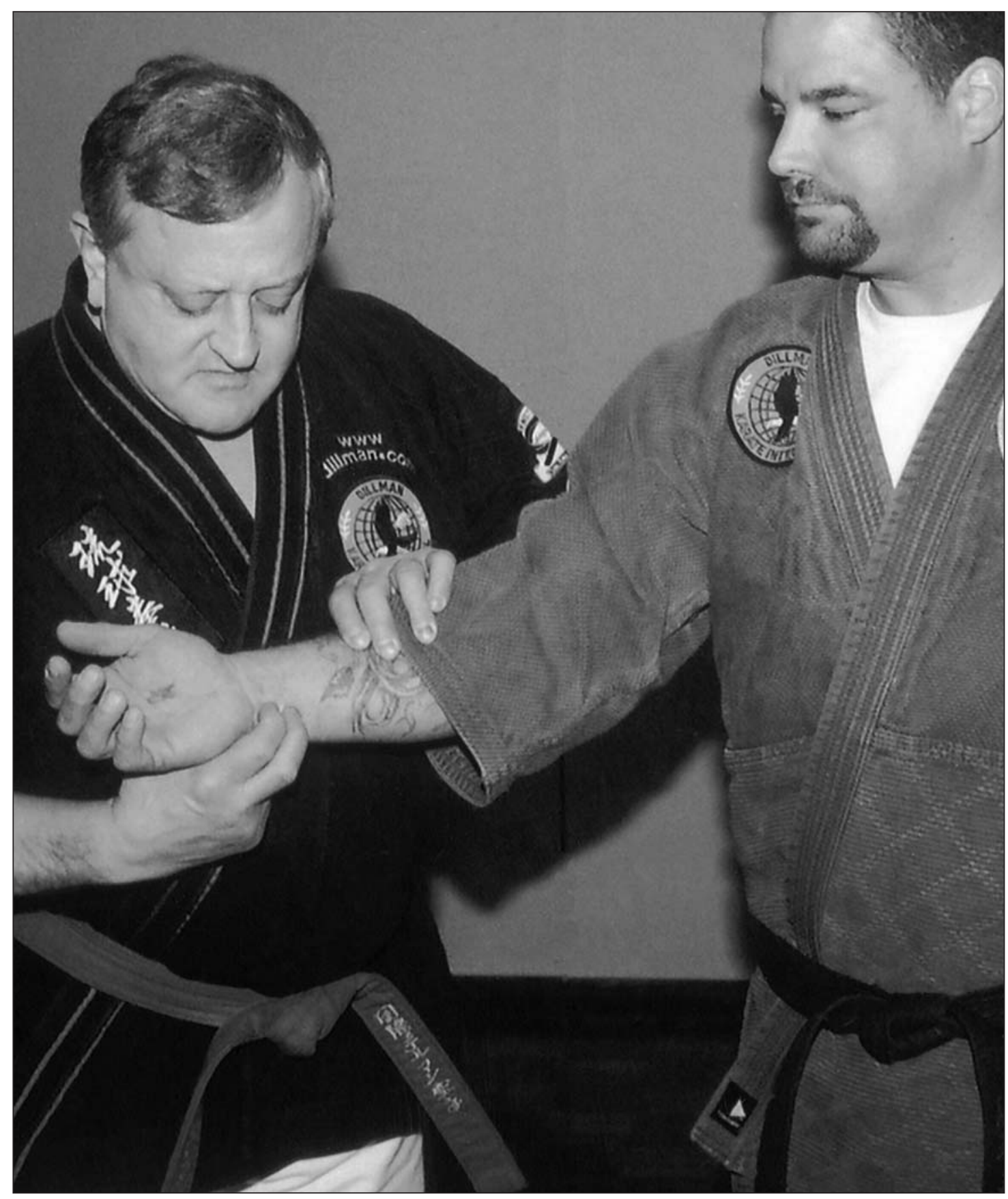


Prácticamente todo el mundo que haya entrenado en las artes marciales de Okinawa o Japón durante las tres últimas décadas estará familiarizado con el nombre de George A. Dillman. En 1982 fue descrito por el Official Karate Magazine [Revista Oficial de Kárate] como "uno de los mayores campeones que nunca haya conocido el kárate” (noviembre de 1982). Fue cuatro veces campeón nacional entre 1969 y 1972, y durante este periodo fue clasificado regularmente por muchas de las principales publicaciones de kárate entre los diez mejores competidores de los EE.UU. Desde entonces, su progreso en el kyusho-jitsu (teoría de los puntos de presión) ha enviado "ondas de choque" a través de gran parte de la comunidad de las artes marciales, y ha llamado la atención sobre ciertas prácticas tradicionales.

Se han escrito volúmenes sobre los aspectos técnicos de este sistema. Lo que ha recibido de algún modo menos atención -quizá eclipsado por el tremendo interés en los aspectos prácticos de este arte- es el examen de las ideas, principios y creencias sobre los que se basa. El 21 de febrero de 2004, en Freehold, New Jersey, tuve la oportunidad de plantearle un cierto número de cuestiones sobre temas tales como historia, tradición, ética e incluso filosofía. Lo que sigue es una profundización excepcional en un aspecto diferente de un hombre al que mucha gente aún hoy conoce, y que quizá otros quieran tomarse el tiempo para llegar a hacerlo.

\section{Entrevista}

\section{Peter Hobart (PH): Por favor, aborde la relación entre el combate con puntos de presión y el combate competitivo convencional}

George A. Dillman (GD): Mi kárate siempre se ha conformado como una defensa personal real -algo que pudiera funcionar en la calle-, incluso cuando destruí mis katas y formas antes de considerar los puntos de presión, tenía en mente "¿Cómo funcionará esto en una situación real de pelea callejera?”. En el ejército (policía) tuve numerosos encuentros en los que tenía que manejar algunas situaciones problemáticas, y me di cuenta que algunas técnicas de artes marciales de las que hablábamos en el dojo simplemente no funcionaban, y me di cuenta de esto pronto, así que tuve suerte. Sin embargo, me siento afortunado de haber sido un competidor deportivo ya que, de haber ignorado esto para llegar a los puntos de presión -cosa que habría hecho probablemente, por completo-, si hubiera ignorado el lado deportivo de ello, habría carecido de la habilidad básica que siempre he dicho a la gente que debe tener.

Tenemos gente que está practicando las técnicas de los puntos de presión hoy en día que no compite, que no combate. Probablemente ellos nunca hayan estado en una situación real de defensa personal y no se puedan defender ellos mismos. Pueden aprender todos los puntos de presión del mundo, pero yo, durante mi periodo deportivo, aprendí todas las cosas que realmente se necesitan para aplicar los puntos de presión en una situación real, y desarrollé el timing, la distancia y la coordinación. Si tú no haces combates de entrenamiento en tu dojo, si tú no haces parejas para practicar defensa personal, simplemente no puedes hacer técnicas de puntos de presión. Quizá puedas tirar a uno o a dos, aplicando una forma de escape básica, pero para una defensa personal completa necesitas desarrollar el timing, la distancia y la coordinación. Esto sucede -y sucede tanto más en un torneo- cuando estás bajo presión, ya que ahí tienes la misma presión, sino mayor, que la que tendrías en una situación en la calle, ya que hay miles de personas gritando tu nombre o el del oponente. (página previa)

George Dillman mostrando puntos de presión en el brazo.

Todas las fotografías son cortesía de George Dillman. 
Al mismo tiempo, esto fue lo que me hizo mirar a los puntos de presión, esto es lo que me ayudó a encontrar a Hohan Soken, y esto es lo que me hizo preguntarle, ya que sabía que estábamos careciendo de algo. En torneos de competición había muchas veces -y era el modo en que se realizaba entonces, ya que no había equipo protector- en las que realmente yo daba un puñetazo a algunas personas, y quería tumbarlos, y ellos no caían. Me dijeron: "Un puñetazo mata", y yo pensé que me estaba perdiendo algo, ¿qué era? Porque golpeé a este hombre tan fuerte como pude y ellos me estaban recompensando con un punto. Ahora un punto es fantástico, pero en una pelea callejera no quiere decir nada... Si yo te pongo en el ring con Mike Tyson y él te golpea, va a ganar. Tienes que evitar ser golpeado y tienes que ser capaz de alcanzarle, y entonces vas a ganar.

PH: ¿Puedes hablar de Hohan Soken (nacido en 1889), Seiyu Oyata, y tu primer descubrimiento de la teoría de los puntos de presión?

GD: Me di cuenta de que me estaba perdiendo algo y me di cuenta de que tenía que haber algo en la kata porque la gente estaba haciendo ahora sus propias katas y formas con música, y sin embargo en Oriente eran leales a la kata básica Pinan, Naihanchi. Ellos eran leales a las katas básicas y las enseñaban y hacían con una mirada diferente en sus ojos, usando ki (fuerza interior), usando el enraizamiento, realizando las cosas de un modo completamente diferente. Me di cuenta de eso, y me di cuenta de que en este país, ya que no aprendimos los secretos, estábamos inventando las cosas, y no quería caer en esto. Le pregunté a Hohan Soke y fue cuando él me dio una respuesta decente.

Cuando tuve las respuestas, era como deprimente. Había gastado veinte años aprendiendo esas katas, y ahora, de buenas a primeras, no había bloqueos, todo tenía un significado serio -cada movimiento, en cada kata-, y eso era justamente lo que no sabíamos, y estaba justo enfrente de tus ojos. Yo estaba realmente enfadado conmigo mismo, que no me lo creía. Las respuestas verdaderas estaban justamente enfrente de mis ojos y no las vi... necesité torneos de competición para llegar hasta donde estoy hoy... Que fuera bueno en la kata fue lo que hizo que Hohan Soke trabajara conmigo. Me dijo, "Haces una kata tan bella que me duele aquí

Dillman con Hohan Soken.

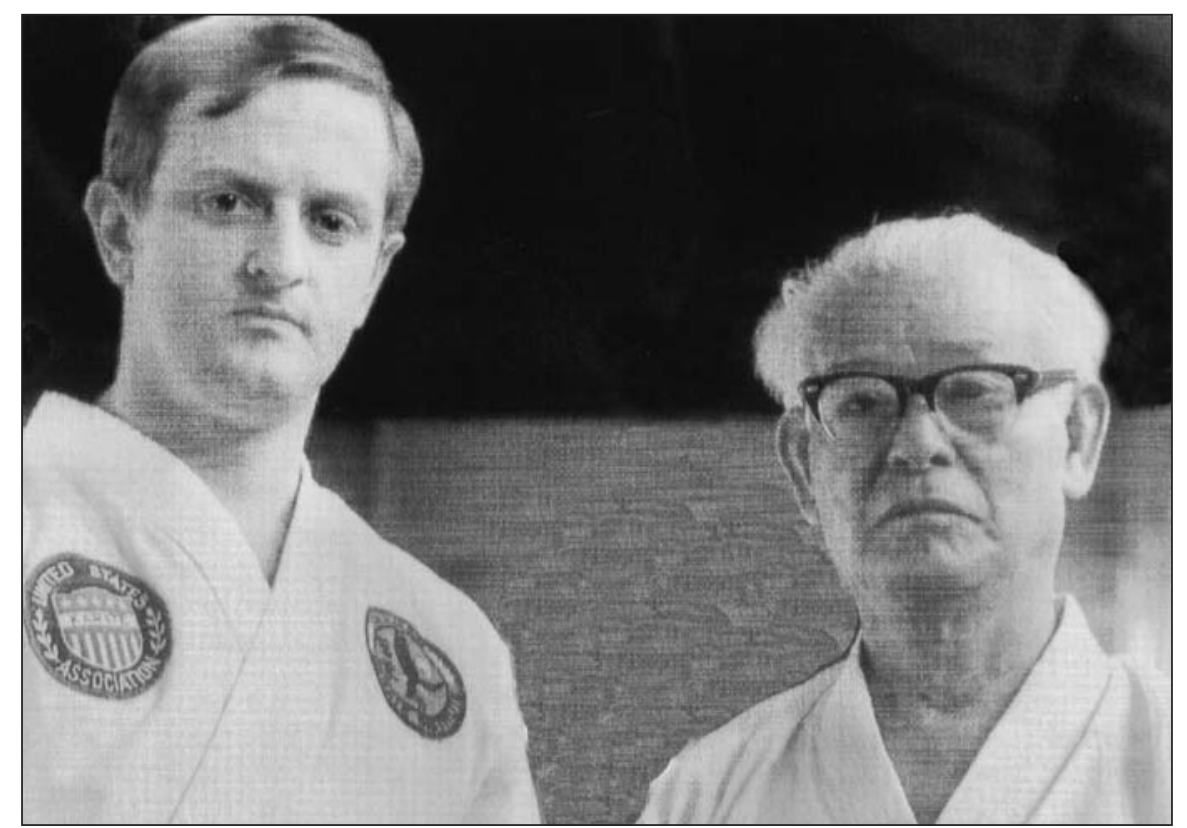


(indicando su corazón) ver que no conozcas la respuesta. Haces la kata incluso con espíritu. En Okinawa procuramos que se tenga espíritu para tener kata. Tú tienes espíritu. Lo que no sabes es lo que estás haciendo con los movimientos... esto es lo que necesitas para ser un maestro en mi país".

En 1983 me topé con Seiyu Oyata. Tan pronto como hizo su primera técnica y dijo "Esto está fuera de la kata", y lo rompió, no estuvo en la lona ni diez segundos, yo me incliné -mi mujer estaba allí- y susurré en su oído: "Eso es lo que Hohan Soken hacía. Esto es lo que Hohan Soken estaba intentando hacer entender. Esto es sobre lo que tratan mis notas. Tengo anotaciones de esto -de lo que está haciendo justo ahora-, ahora lo estoy comprendiendo. Seiyu Oyata me dio las llaves para cruzar la puerta. Tenía la puerta, tenía el sendero, tenía las katas, tenía la idea general, sabía que todo era más serio, sabía que no había bloqueos, pero no sabía lo que eran.

\section{PH: ¿A qué se parece enseñar durante más de quince años en colaboración con Wally Jay, Leo Fong y Remy Presas?}

GD: Asistí a los seminarios de estas personas (Wally Jay, Leo Fong, Remy Presas), les tuve en mi escuela impartiendo seminarios y nos pusimos a hablar sobre la técnica y terminamos colaborando. Desde el momento en que le vi (Wally Jay) en la lona supe que necesitaba su jujutsu del Pequeño Círculo para lo que estaba haciendo. Tenía un maestro de Okinawa -Seiyu Ogata-, quien decía que si realmente querías encontrar el secreto necesitabas a un buen especialista de jujutsu. Entonces vino Wally Jay, que era el mejor especialista de jujutsu, y me di cuenta, el día en que entró en el dojo, que era el jujutsu del Pequeño Círculo lo que me estaba perdiendo. Yo era capaz de golpear a las personas y de hacerles daño, aturdirlos, pero no era capaz de ponerlos fuera de combate tan bien como lo hacía después de estudiar con Wally Jay. Es la teoría del Pequeño Círculo que él enseña y practica lo que completó mi arte. Luego él mismo encontró que utilizar los puntos de presión le ayudaba a completar su arte. Tanto él como yo utilizamos técnicas de presión de puntos, pero no sabíamos como todas se engranaban en conjunto, y ahora lo sabemos.

Por lo tanto, empezamos a colaborar, lo que me llevó hasta Remy (Presas), y Remy vino y empezó a trabajar conmigo en desarmar a las personas, alejar las armas, y trabajamos sobre los puntos de presión. Realizamos algunas sesiones por las que daría cualquier cosa por tenerlas en vídeo. Hacíamos sesiones de entrenamiento realizando y compartiendo técnicas que un artista marcial medio encontraría increíbles. Era fantástico. Remy, lo echo mucho de menos. Siempre le digo a la gente que él era mi agente. Remy podía llamarme: "Tu y yo impartiremos un seminario. Lo haremos en Atlanta, Georgia”. Yo preguntaba: “Impartiremos?”. Y decía: "Si, si, debes estar allî" ¡Y después colgaba! Y hacía lo mismo con Wally y nos ponía a los tres juntos, y esto fue tremendo durante casi quince años.

\section{PH: ¿Qué hace a un maestro? ¿Cómo fueron tus encuentros con estas personas?}

GD: La habilidad para enseñar, la habilidad para hacer que puedas hacerlo. Hay muchas personas que son buenos artistas marciales pero no son buenos enseñando. Bruce Lee era maravilloso haciendo entender los conceptos. Sólo trabajé con Bruce Lee tres veces, pero él mejoró la velocidad de mis manos. Me dijo inmediatamente: "Tienes que mejorar la velocidad de tus manos y pies. Tienes mucha fuerza, buenas técnicas, pero puedo golpearte tres o cuatro veces antes de que tu puedas hacerlo"
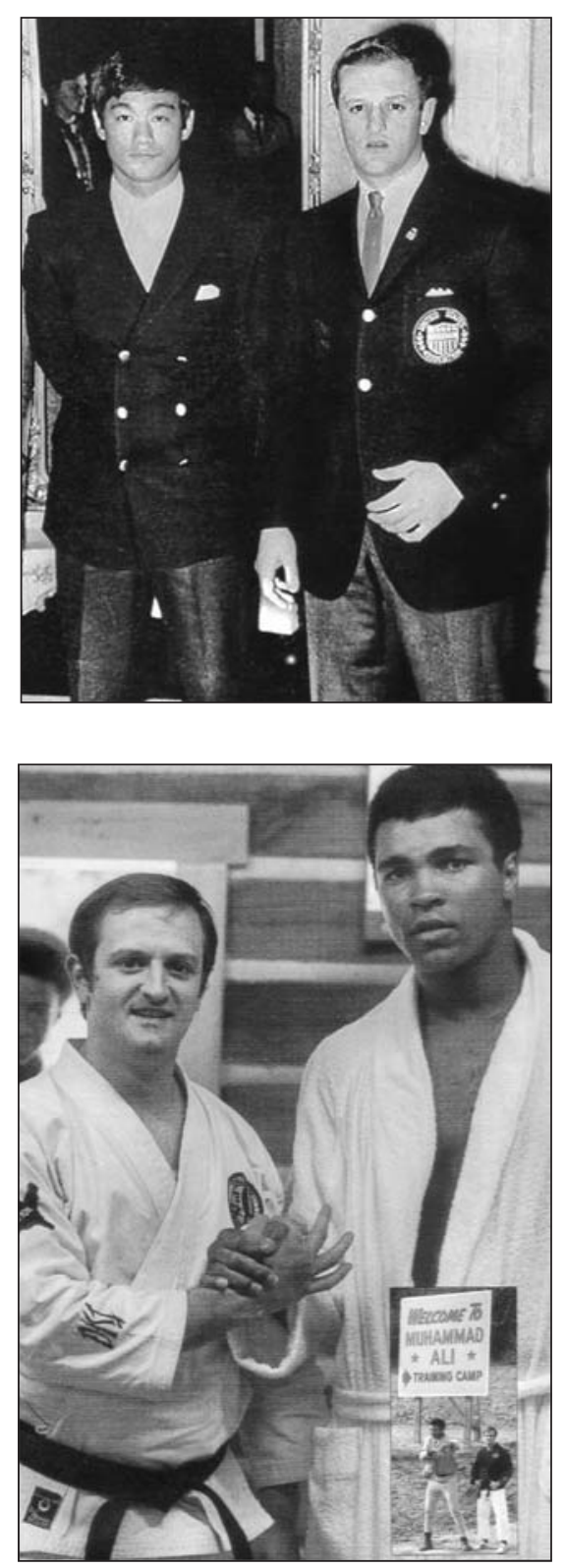

Entre los asociados de Dillman que han influenciado en sus estudios sobre las artes marciales están Bruce Lee y Muhammad Ali. 

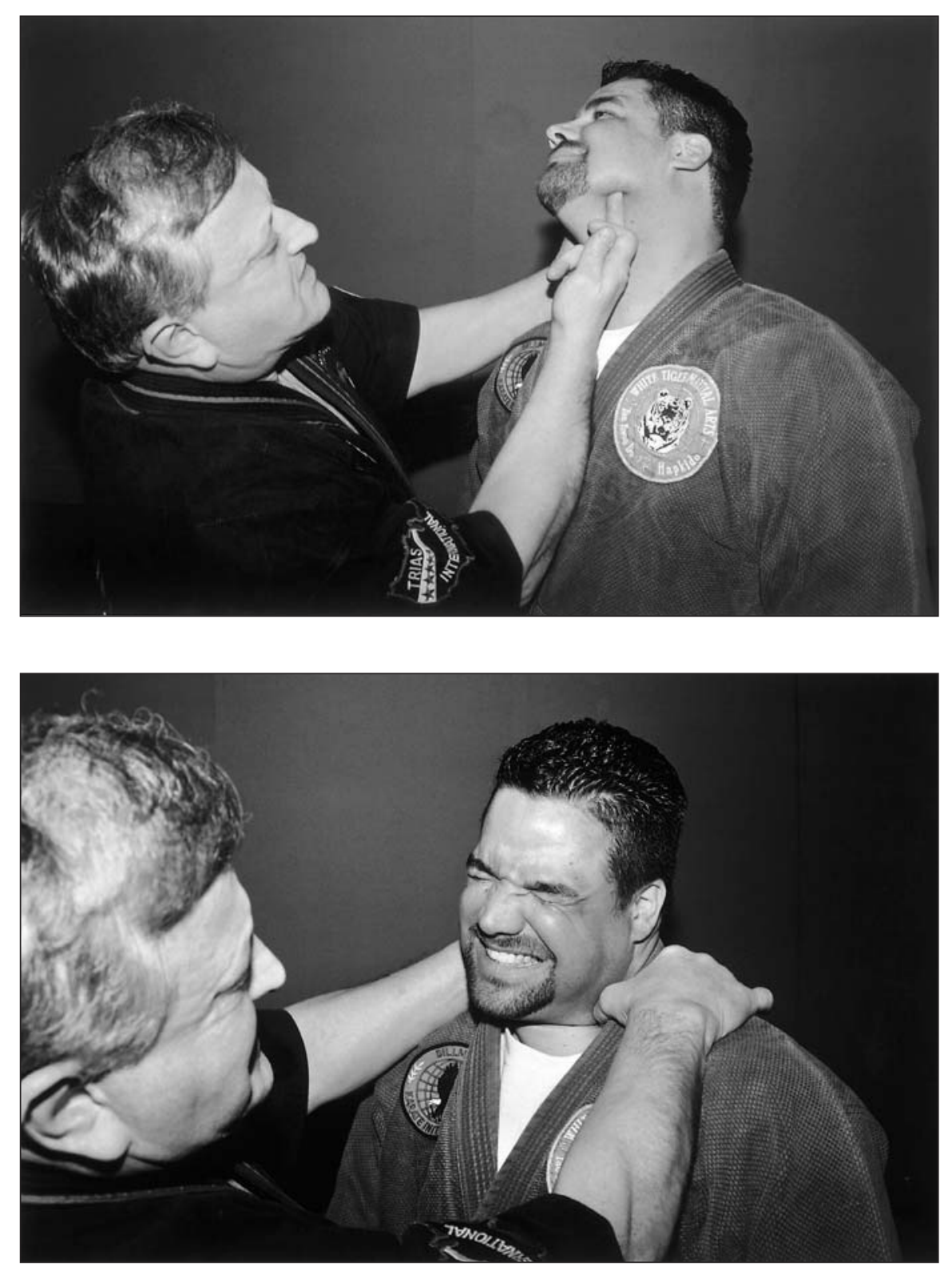

Explicando la localización de los puntos de presión en la mandíbula, cuello y muñeca, y cómo la teoría es aplicable en la práctica de las artes marciales.

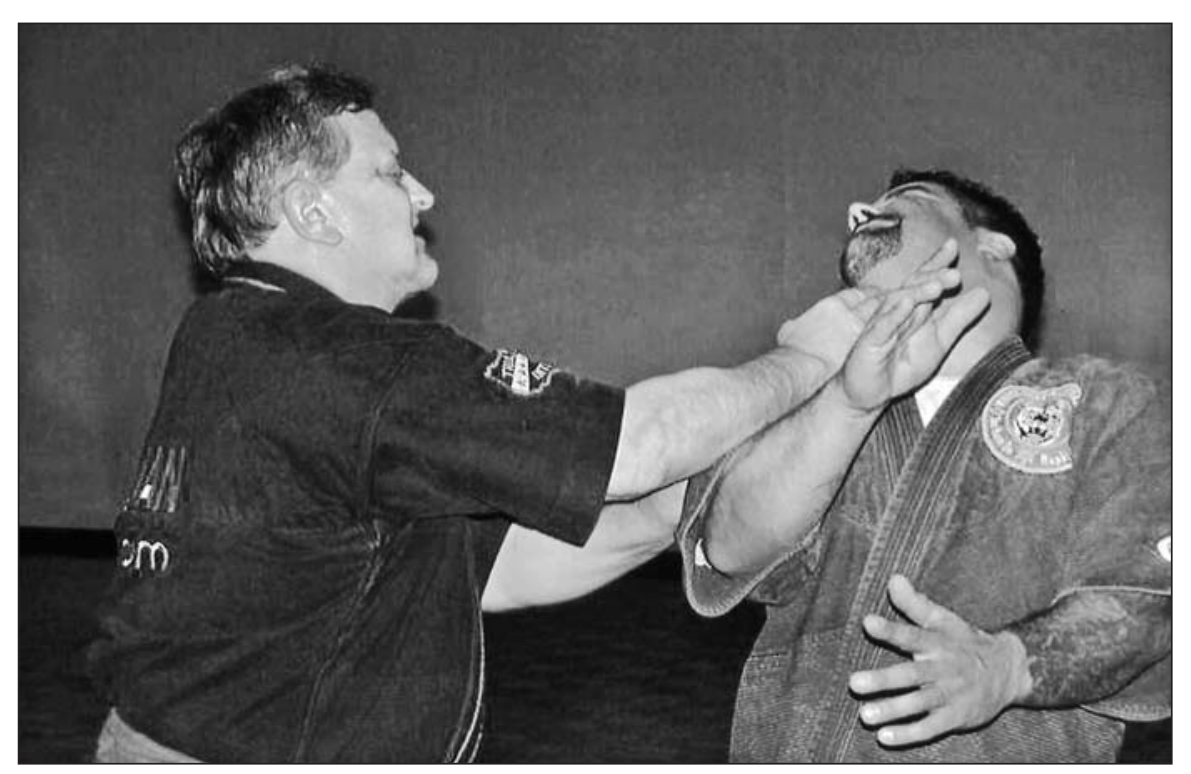


¡Después lo hizo! Pero también me enseñó como hacerlo. Después la velocidad de mis manos mejoró.

Daniel K. Pai fue un inigualable maestro mundial. Tenía un gran número de técnicas, pero falleció a destiempo, como Remy Presas, antes de lo que cabía esperar. Danny Pai fue uno de los mejores profesores de gongfu de la época. Cuando tenía charlas sentado a la mesa con Bruce Lee y Danny Pai solamente me sentaba y escuchaba. Y estaba aprendiendo más de lo que la mayoría de las personas aprenden en toda su vida en el dojo, sentado a la mesa. Eso era asombroso, que esas personas pudiesen enseñar sólo con palabras, después podían levantarse y demostrarlo.

Robert Trias fue uno de los primeros americanos en practicar las artes marciales, y era una persona tremenda y un fuerte pegador, ¡no te gustaría recibir uno de sus puñetazos! Yo no era de la talla de Robert Trias. Era un hombre grande, inmenso, por tanto cuando golpeaba no querías estar en frente de él. Pero Bruce Lee no lo era, y Bruce Lee me hizo prestar atención a la velocidad y a la fuerza, porque Bruce era un individuo pequeño $-1,70 \mathrm{~m}$. y $56,6 \mathrm{~kg}$.-, e hizo que me diera cuenta de que esa era la respuesta. Fue una casualidad que estuviese con las personas adecuadas en el momento oportuno. Sin embargo, yo tengo algo de mérito porque busqué a estas personas, ellas no me encontraron.

Ed Parker y yo éramos amigos -Ed Parker y Danny Pai eran primos carnales-, Danny me presentó a Ed Parker y Ed Parker me presentó a Bruce Lee. Bruce Lee me presentó a Wally Jay y Leo Fong. Bruce Lee se sentó en mi casa y dijo: "Yo no vengo muy a menudo por aquí, ¿Quiénes son los luchadores más duros de la Costa Este? Alguien con el que, si tuvieses que tener un combate real, sabrías que has de prestar atención y usar las dos manos". Le di un par de nombres de personas en las que pensé en aquel momento, personas que yo respetaba y que eran luchadores grandes y fuertes. Guardó esto en su memoria. Yo pregunté: "¿Y en la Costa Oeste?". Dijo: "Hay varios", y los nombró.

Lee dijo: "Hay un hombre allí llamado Wally Jay. Tienes que conocerlo y entrenar con él en algún momento. No es una persona sin sentido. Hazle una pregunta y él no la responderá verbalmente; te lleva a la lona y te la demuestra, y no puedes hacer nada. He visto a algunos de los mejores artistas marciales del mundo ir a la lona con Wally Jay y ser derrotados. Tienes que entrenar con él. Leo Fong es uno de los boxeadores más duros que nunca me he encontrado. Tienes que pegarte con él, y tienes que estar listo para derribarlo porque seguirá viniendo". Fue después de que Bruce Lee falleciese cuando fui a buscar a Wally Jay y Leo Fong. Fui a Canadá a encontrarme con Wally Jay, y llevé a un buen grupo de mis estudiantes para que lo viesen trabajar, haciendo su trabajo, y me aproximé a él haciendo un seminario en mi escuela.
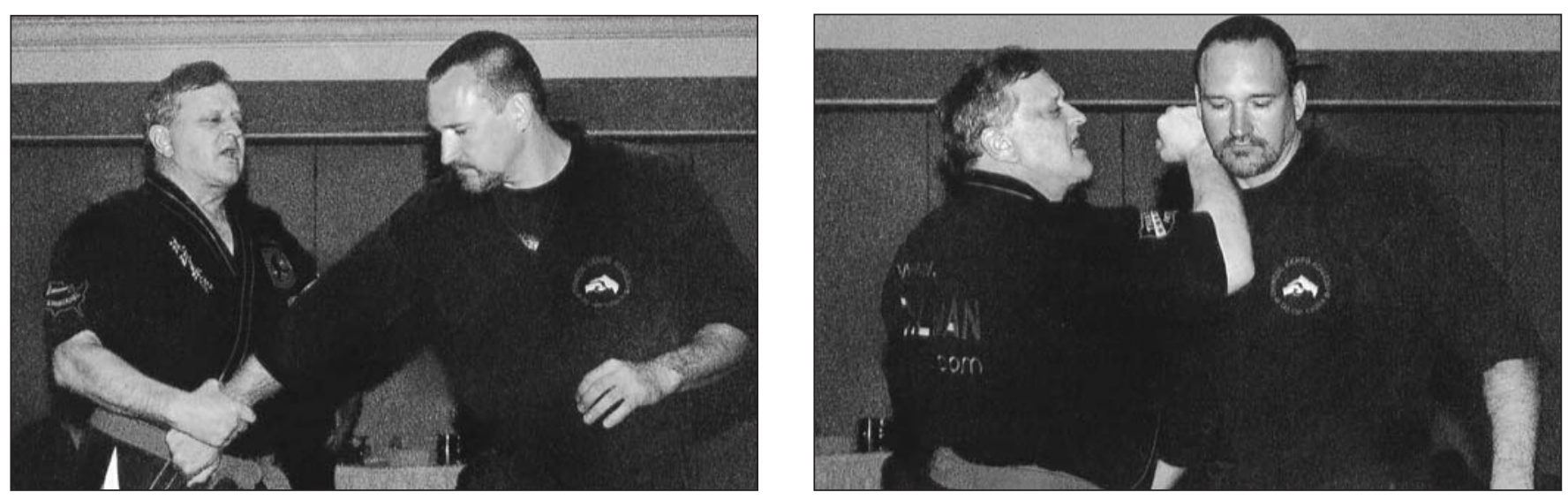
PH: ¿Sobre la importancia de enseñar técnicas de curación en conjunción con la práctica de artes marciales?:

GD: Tres razones. La razón ética, la razón práctica... puesto que como artista marcial tienes que aprender a invertir lo que has aprendido a hacer con las artes marciales. Si haces daño a alguien, si lo pones fuera de combate, tienes que aprender el modo de revivirlo. La tercera razón es que yo, y mucha otra gente a la que interesa la teoría de los puntos de presión, estamos buscando formas de prolongar nuestras vidas... y creo que estamos en el camino. Estamos encontrando formas mejores para restaurar nuestra energía ki, estamos encontrando formas de recuperarnos después de los seminarios de modo que no estamos tan cansados y débiles, y todo esto lleva a la parte curativa. No sólo nos estamos curando, sino que estamos aprendiendo cómo realizar la curación dentro de nosotros mismos.

La cosa que he encontrado es que la mayoría de artistas marciales que están en esta onda llegan a nonagenarios con completa flexibilidad. Hohan Soken figura al final de mi vídeo practicando formas, y tenía 92 años. Ese vídeo salió dos semanas antes de que él muriese. Él no sabía que iba a morir en dos semanas, pero su cuerpo estaba reduciendo su actividad... Lo que era sorprendente es que a los 92 años él pudiese hacer una kata llamada Chinto y saltar en el aire y lanzar dos patadas, y podía ir al suelo con una pierna y levantarse, y podía hacer un giro completo de 180 grados sin caerse. Si sales a la calle y coges a un hombre medio de 92 años y haces que realice un giro completo seguro que va a caerse. Él tenía un control completo de su cuerpo y de su energía, él sabía cómo se mueve la energía, en espiral hacia arriba y hacia abajo... Cuando giras y te mueves en una kata estás con-

Dillman mostrando técnicas de resucitación.
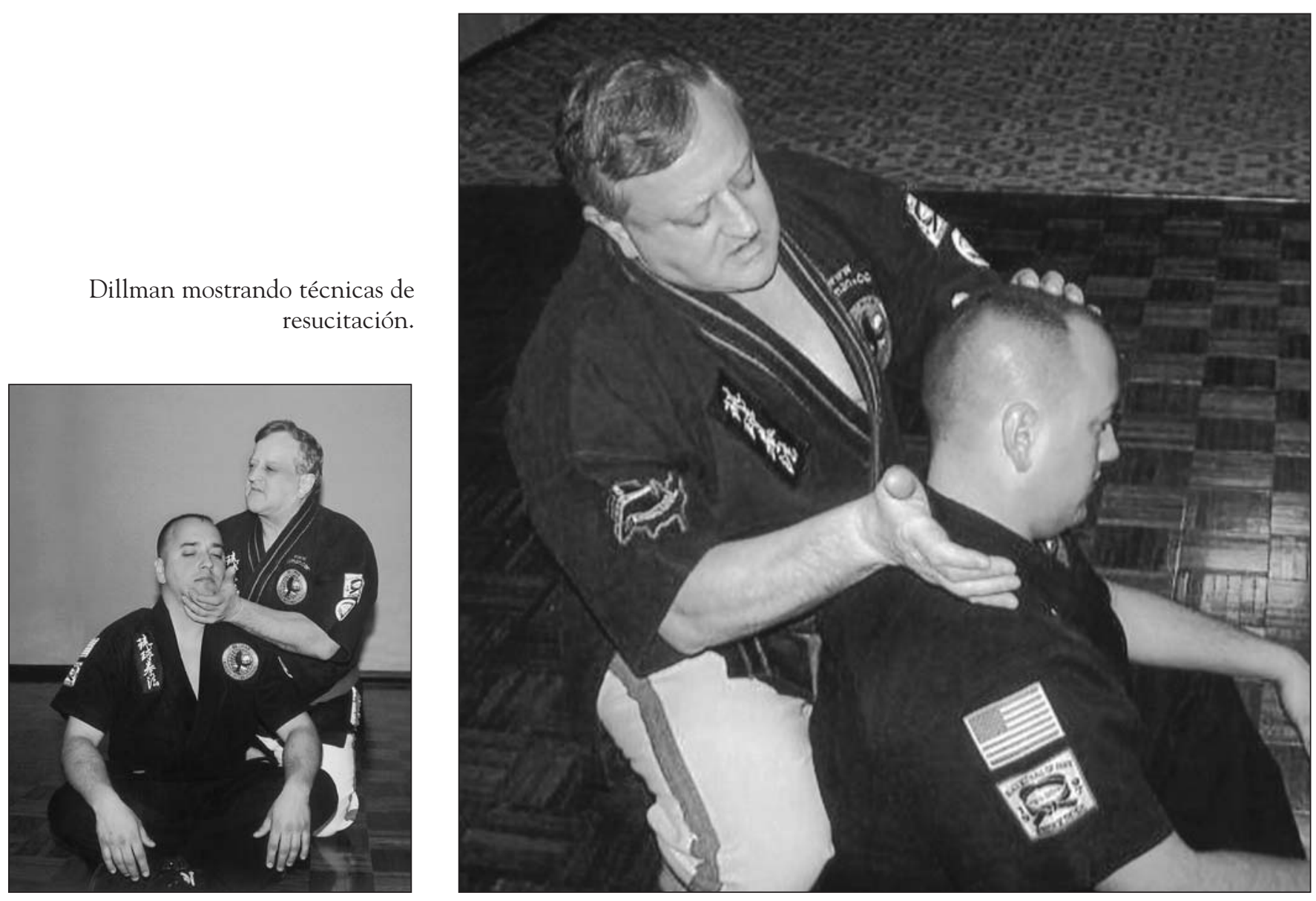
trolando tu energía y enviándola arriba y abajo a través de tu cuerpo. Si sabes como hacer esto se generará salud y flexibilidad.

\section{PH: ¿Cuáles son los aspectos humanos del kyusho-jitsu, la teoría de los puntos de presión?}

GD: El arte que yo enseño es mucho más humano que golpear a la gente en la nuez, dar con los dedos en los ojos o dar una patada en la ingle -esto es lo que aconsejan en la mayoría de escuelas de kárate-. Están enseñando cortes de ojos y cómo ahuecar las manos y golpear en ambos oídos. Están enseñando a desgarrar la nuez o a golpear la garganta, cómo golpear la entrepierna. Tuve que examinar todo esto en $\mathrm{mi}$ mente cuando me inicié en los puntos de presión, porque me di cuenta de lo letales que son y pueden ser... esto es por lo que los llamamos "puntos vitales". Puntos vitales como los ojos, la nariz, la garganta y la entrepierna. Tenemos puntos de presión -hay unos 361 por todo el cuerpo- y tenemos variantes de aplicación porque los necesitamos en diversas situaciones de defensa personal. No siempre puedes llegar a los ojos, nariz, garganta o entrepierna, puesto que estas zonas tienen una defensa natural. No hay nadie en el mundo que no se eche para atrás ante un golpe a los ojos o a la entrepierna... Hay puntos de presión que dan exactamente el mismo resultado.

\section{PH: ¿Qué importancia tienen las emociones en la técnica de las artes mar- ciales?}

GD: Puedes leer en cualquier libro de artes marciales -cualquier buen libro- que debes estar contento y seguro mientras combates. No te contagies del enfado de tu oponente. La furia niega la furia. Si coges a dos personas que estén enfadadas, que se estén golpeando la una a la otra, no se pueden hacer daño. Coge a una que esté enfadada, a otra que se esté riendo, y que la persona contenta golpee al tipo que está enfadado, y el tipo enfadado caerá al suelo... he estado en varios encuentros de defensa personal y no me había dado cuenta, pero estaba contento y sonriendo porque estaba confiado. Sabía que estaba preparado para enfrentarme a este tipo, y él estaba delante de mí muy enfadado. En aquel momento no comprendía que las emociones y mi estado de ánimo alegre iban a ayudarme a derribarlo.

\section{PH: Afirmas que "La siguiente gene- ración siempre será mejor que la pasada. Al menos esta debería ser la meta de cualquier buen profesor. Los estudiantes siempre deberían ser mejores y superar al profesor" $i$ Es esto cierto aún?}

GD: Oh, si, tienen que hacerlo para que esto siga vivo. En un momento yo estuve preocupado por algo que me estaba pasando. Yo abrí un secreto de las artes marciales, y estaba preocupado por algo que me estaba pasando sin ver esto, sin saberlo. Por tanto empecé

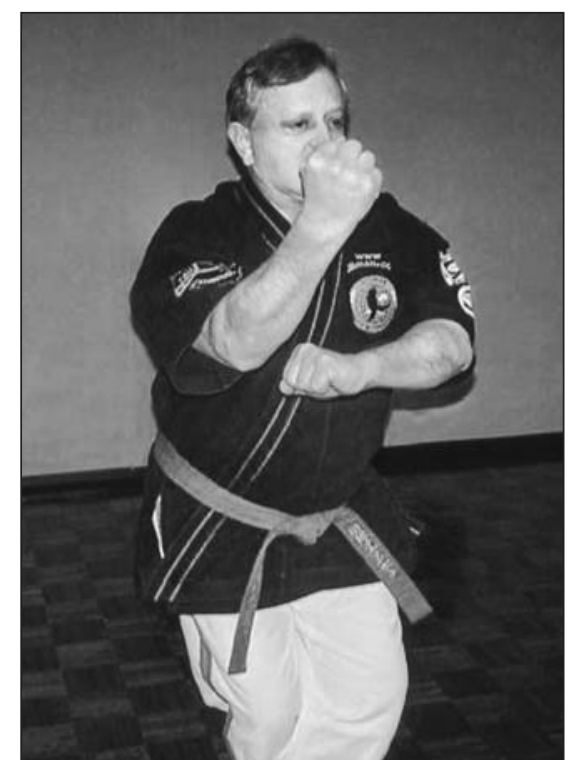

Dillman demostrando cómo las posturas correctas ayudan al conjunto de las técnicas.

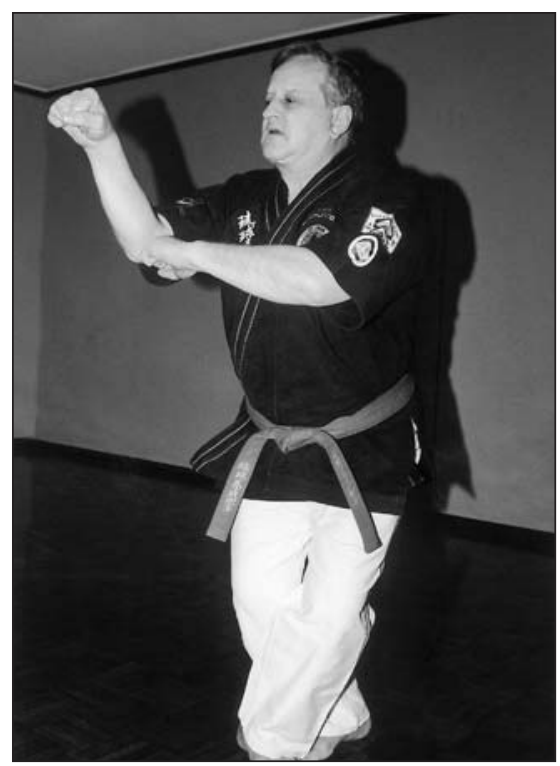


a enseñarlo, pensando si podría enseñar a algunas personas para que pudiesen transmitirlo. Ahora hay miles a lo largo del mundo. Puedo nombrar países de todo el mundo que están practicando técnicas de puntos de presión... Hemos superado un periodo en que la gente estaba dejando las katas y formas, y esto estaba basado en una afirmación que hizo Bruce Lee, sobre la que yo le pregunté personalmente antes de que muriese. Él no quería decir lo que luego otros han escrito. Bruce Lee decía que ya no necesitaba katas y formas para combatir... A todo el mundo le pareció que él no las había necesitado... Él dijo: "La kata y la forma es tu aprendizaje, como

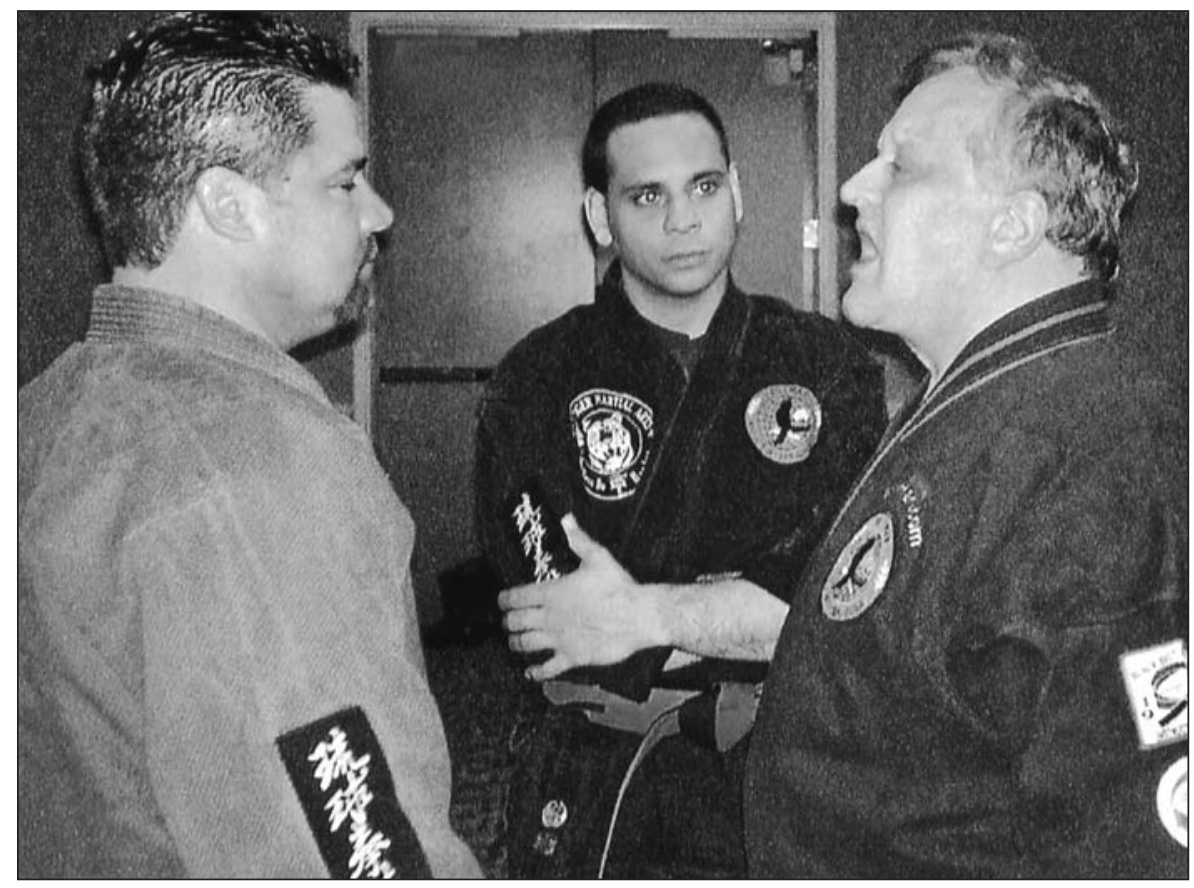

La respiración adecuada y el uso del sonido son parte del entrenamiento de las artes marciales.

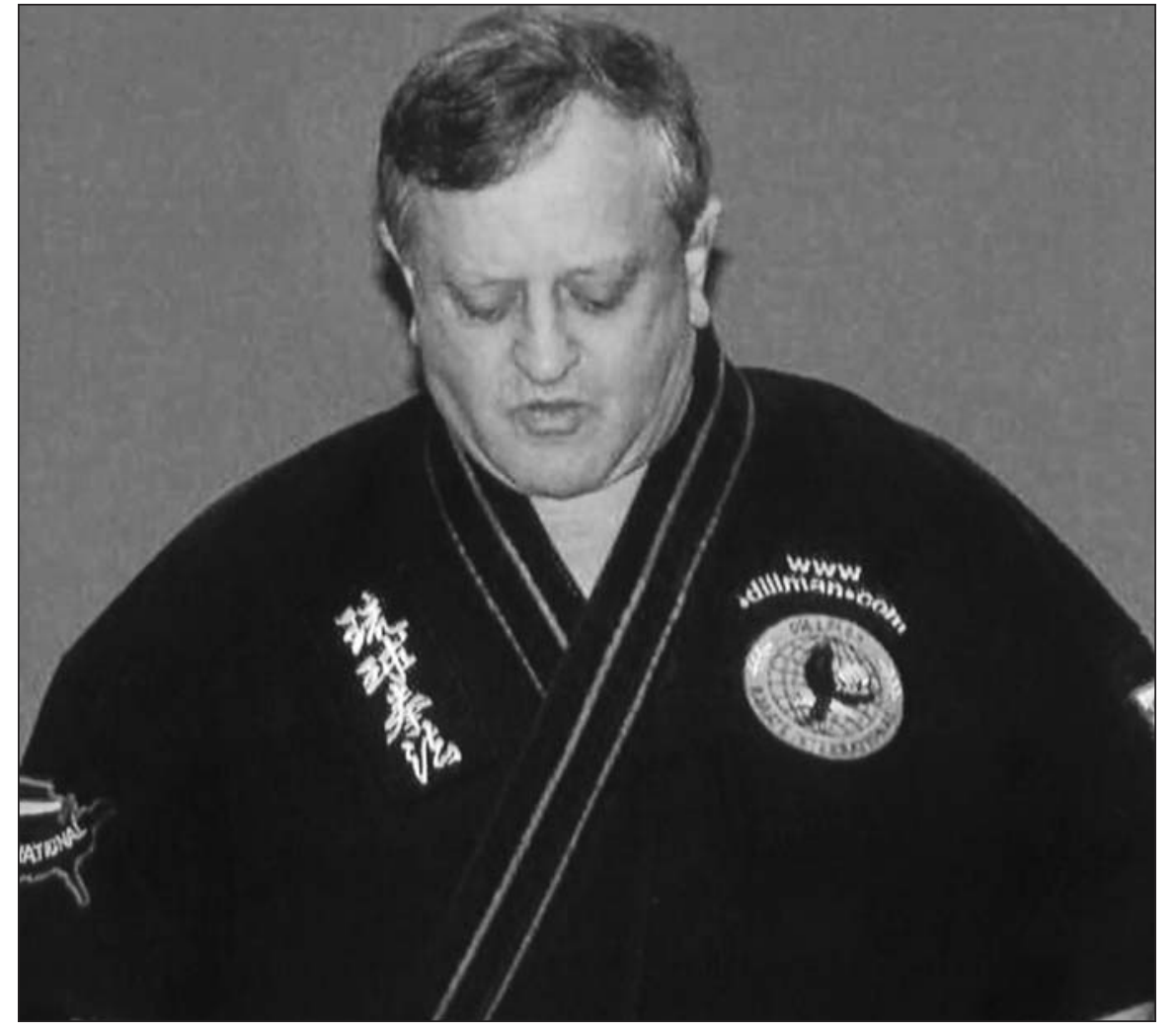




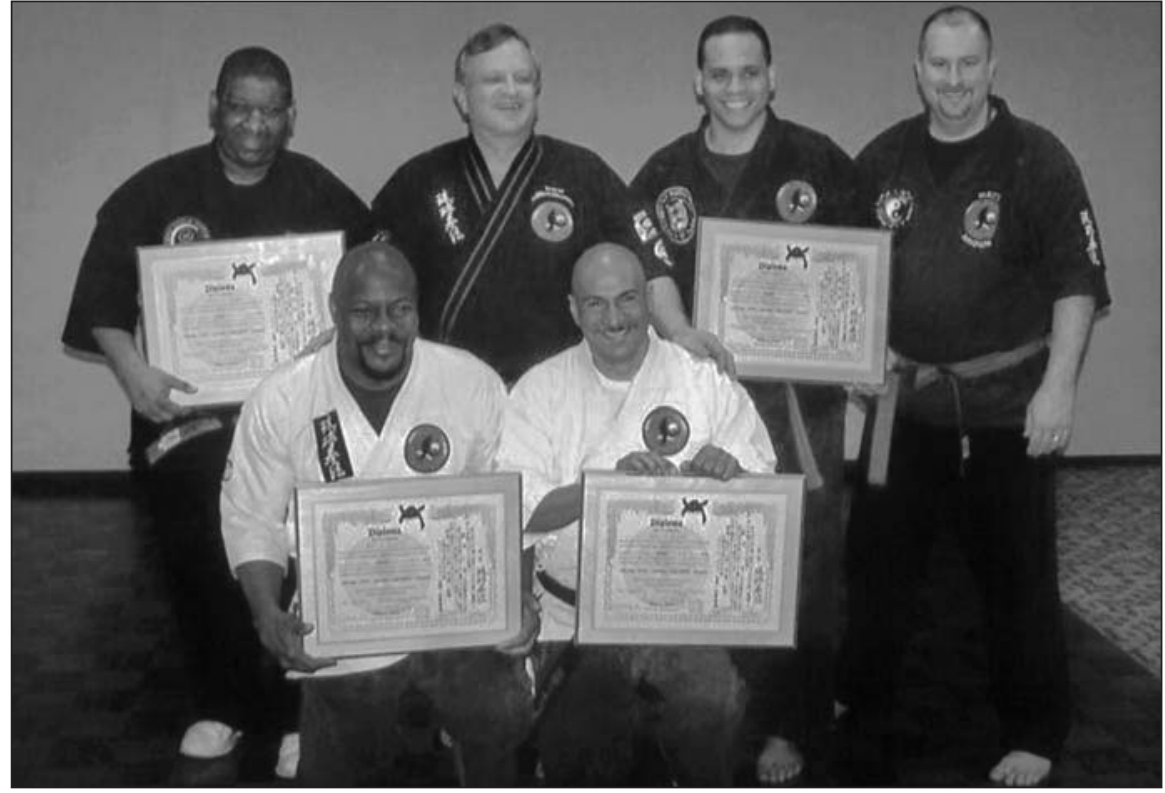

copiar el alfabeto. Estás aprendiendo a escribir. Si ahora mismo quieres escribir una carta a alguien no vas a copiar el alfabeto, nunca más. Pienso que puedo parar de hacer mis katas y formas y luchar del mismo modo, ahora". No quiso decir que no tuviesen que hacerse en absoluto.

\section{PH: ¿Cómo continuará tu sistema de lucha en el futuro?}

GD: Quiero hacer una historia de todo esto... Remy Pesas tenía una historia en Black Belt Magazine hace varios años, sobre quién debería encargarse si a él le pasase cualquier cosa. Ahora estamos trabajando con Black Belt haciendo esta historia, y poniendo la descripción de cada uno. Pero tengo un montón de gente joven que están realmente muy bien entrenados, y se que tomarán el testigo, gente como Bill Burch, el Dr. Chas Terry -él les medico y acupuntor-, Ed Lake, que asistió a una escuela de acupuntura y que probablemente sepa más acerca de los puntos de presión que cualquiera del sistema, ya que está entrenado como médico y herborista. Dusty Seal es un hombre joven con muchísimos conocimientos... el hombre que me ayuda a escribir los libros, Chris Thomas... me comunico con él diariamente. Es también presbítero... por tanto hablamos sobre varios aspectos de la defensa personal así como del significado de todo esto, siguiéndole la pista.

\section{PH: ¿Qué te gustaría que recordasen las generaciones futuras sobre tu influencia en las artes marciales?}

GD: El hecho de que hice un gran cambio en las artes marciales, al menos fuera del recinto cerrado de Oriente... hay personas que incluso están usando mi teoría sin comprenderla bien, pero al menos están pensando sobre sus formas, sus katas, y están intentando sacar mejores movimientos. Por tanto creo que he hecho un gran cambio con el que estoy contento, y creo que esto va a continuar por ahora. Si muero mañana creo que va a continuar porque hay miles de personas que ahora están enseñando esta teoría. Hay muchas cosas que ellos van a tener que hacer, desarrollar y descubrir por sí mismos, que posiblemente no les haya enseñado si no estaban en el lugar correcto en el momento adecuado, pero tienen que ser capaces de desarrollarlas y comprenderlas. Di el modelo para hacerlo, di el mapa.
El paso de la tradición marcial continúa a través de las generaciones. Aquí, Dillman aparece con estudiantes que están siendo ascendidos en su sistema mediante certificados.

\section{Agradecimiento}

El autor agradece especialmente a todos aquellos que aparecen o han ayudado en este artículo: Angel Vazquez, Lynne A. Broughton, Donald Hagans, Carl Bunch, Chris Menchini, Siobhan R. Knuttel, Richard O'Hagan, Cesar Albacete, Jr., Rachele Addonizio, Michael La Sala, Doug Moore, Edward Afanador, Sterling I. Johnson, Ralph Karp, Matt Brown, Laureen Eile y Roy Wagner. Sobre todos, expresa un profundo agradecimiento al Sr. George Dillman, por compartir su tiempo y conocimientos con nosotros. 